\title{
WhatsApp Platform as a Dental and Oral Health Online Communication Forum for Dentist, Nurse, and Elementary Teachers
}

Titiek Berniyanti, Taufan Bramantoro, Gilang Rasuna, Achmad Zamzam, Aryo Dwipo Kusumo, Aulia Ramadhani

Department of Dental Public Health, Faculty of Dental Medicine, Universitas Airlangga, Surabaya, Indonesia

\section{Abstract}

Aims and Objectives: To connect the dentists, dental nurses, and school teachers so that they can produce a discussion forum about dental and oral health. Materials and Methods: The method in implementing the empowerment program was grouped into three stages, that is, pretreatment stage through problem mapping, problem prioritization, determination of programs related to existing issues, and coordination. It was then followed by the stage of program implementation and evaluation of the activity. Results: Dentists, dental nurses, and student health unit/sport teachers were able to access online communication forum through WhatsApp without constraint. Conclusion: This online dental communication forum was an integrated system that built communication between related agencies to increase the minimum number of visits of elementary school students to dental services. With this program, the database of dental examination results from School's Dental Health Unit indirectly will also be stored well and owned by each school.

Keywords: Caries, Elementary School Students, Online Communication Forum, WhatsApp

\section{INTRODUCTION}

The development of the health sector is one of the initial efforts to improve public health status, one of which is the presence of a Local Public Health Center. According to National Health Research/Riset Kesehatan Dasar (Riskesdas), in 2013, the prevalence of caries in Indonesia reached 76.2\% with Decayed, Missing, Fillings Index (DMF-T) score of 4.5. ${ }^{[1]}$ This is also supported by the 2009 Household Health Survey/Survey Kesehatan Rumah Tangga, which showed that Indonesia's population with dental caries was $73 \%$. Similarly, data from the Ministry of Health of the Republic of Indonesia (Kemenkes RI) in 2009 showed that $89 \%$ of Indonesian children under 12 years had dental caries.

On the basis of the data from Basic Health Research of East Java Province in 2013, the percentage of population with dental caries in the age group 5-9 years was $28.9 \%$ but those who got dental treatment were only $15.1 \%$. According to the data from the Health Department in Surabaya (2013), it can be seen that those who required

\begin{tabular}{|l|l|}
\hline \multicolumn{2}{|c|}{ Access this article online } \\
\hline Quick Response Code: & Website: \\
\hline & www.jioh.org \\
\cline { 2 - 2 } & \\
\hline
\end{tabular}

dental treatment had increased from 2011 to 2012. In 2011, there were 402,098 children who needed dental care, whereas in 2012 , there were 554,917 children. This means that the number of children who required treatment had increased by $152,819 .^{[1]}$

On the basis of the results of epidemiological studies on the severity of caries in grade II and III elementary school students in the working area of East Java Subdistrict Health Center, it was found that $97.3 \%$ of students had caries.

Dental caries is a disease with multifactorial causes. The prevalence and incidence of dental caries in a population are influenced by a number of risk factors such as age, sex,

Address for correspondence: Dr. Titiek Berniyanti, Department of Dental Public Health, Faculty of Dental Medicine, Universitas Airlangga, Surabaya, Indonesia, JI Prof. Dr. Moestopo No.47, Surabaya, Indonesia. E-mail: berniyanti@gmail.com

This is an open access journal, and articles are distributed under the terms of the Creative Commons Attribution-NonCommercial-ShareAlike 4.0 License, which allows others to remix, tweak, and build upon the work non-commercially, as long as appropriate credit is given and the new creations are licensed under the identical terms.

For reprints contact: reprints@medknow.com

How to cite this article: Berniyanti T, Bramantoro T, Rasuna G, Zamzam A, Kusumo AD, Ramadhani A. WhatsApp platform as a dental and oral health online communication forum for dentist, nurse, and elementary teachers. J Int Oral Health 2019;11:213-6. 
ethnic group, dietary patterns, and oral hygiene habits. ${ }^{[2]}$ Caries in children is caused by many factors, including class level, low knowledge of children, experience of toothache, erroneous toothbrushing frequency, and lack of visits to dental and oral health services. Dentists, dental nurses, and teachers have got a role in dental caries prevention in children. In addition, promoting knowledge about the causes and prevention of oral diseases has become an important responsibility of school teachers. ${ }^{[3]}$

To be able to promote oral health care, school teachers must be given empowerment and socialization about dental and oral health. Submission of information will be more effective if carried out in a structured manner and in a clear flow arrangement. Dentists and dental nurses in local public health can share information about dental and oral health with the school teachers. However, the distance between the school and the public health center and also operational hours of the public health center are the obstacles. As one of the important components of the overall health-care delivery system in any country is school health programs, ${ }^{[4]}$ school teachers should be trained in providing oral health education. ${ }^{[5]}$

Community empowerment in the field of oral health is one way to support the implementation of health development, one of them is by empowering health cadres. Activities directed at promotive services, preventive, and referral dental and oral health were carried out on community-based health efforts. ${ }^{[4]}$

The availability of dental and oral health services can affect the frequency of accessing dental and oral health services of children. However, dental and oral care facilities had not been used optimally by the community, especially by parents who had no awareness to check their children's dental and oral health. ${ }^{[5]}$

The past few decades have witnessed a dramatic increase in consumers seeking health information online. Mobile phones, in particular short message service (SMS) and Internet (networking sites), offer health promoters an exciting opportunity to engage personally with a huge number of individuals at low cost. ${ }^{[6]}$ The key elements such as message style, language, and broadcast schedule are directly relevant to future studies using SMS for health promotion, as well as for future health promotion interventions in other mediums that require short formats, such as social networking sites. ${ }^{[6,7]}$

For this reason, intervention was needed as a first step to overcome the oral and dental health of elementary school by making a system of online communication forum through social media WhatsApp, which was expected to be an alternative solution to establish cooperation between health centers and schools in data processing and monitoring each other's referral data for those who needed further treatment based on the results of the periodic dental examination of children in the program as an effort to increase the number of students who visited health services. The purpose of this empowerment program was to connect the dentists, dental nurses, and school teachers so that they can produce a discussion forum about dental and oral health.

\section{Materials and Methods}

The health education method used in this empowerment was a method based on group approach, that is, a small group, consisting of dentists and dental nurses from a health center, and teachers of student health unit from six elementary schools. The number of samples used in this study was taken from total sampling of a number of elementary schools around the working area of Balongsari Public Health Center, Surabaya.

All the respondents who were the subjects in this study had filled the informed consent that stated their willingness for intraoral examination and filling questionnaire. Ethical approval for performing this study has been obtained from Research Ethics Committee of Faculty of Dentistry, Universitas Airlangga, Surabaya, Indonesia, with the ethical clearance number: 136/KKEPK.FKG/VII/2016.

The target of this communication platform program between dentists, nurses, and teachers, was to increase the number of class II and III data of dental and oral health collection in the public health center. The target to be achieved was that dentists, dental nurses in health center, and school health care personnel were able to operate online communication forum properly with a given training.

The electronic media used was laptop, computer, and smartphone. The procedures in the use of online communication forum through social media WhatsApp were as follows:

1. The health center provided directions to the teachers to upload the entire student database contained in each elementary school.

2. Health center provided sample form of student database.

3. Teachers downloaded and filled sample form of the health center in accordance with the student database owned by the school, consisting of class, student name, gender, address, phone number, and then re-uploaded in communication forum.

4. Student database uploaded in communication forum with file name format "Student Data Class (1/2/3/4/5/6)-Name School-Year."

5. Health center downloaded and filled form of decayed, exfoliation, filing Index (DEF-T), DMF, diagnosis, treatment plan, date of reference, and date of treatment on the file, according to the results of dental examination and re-uploaded to the communication forum. 
6. Completed student database with result data of inspection uploaded in communication forum.

7. Teachers downloaded the file as an archive.

8. Teachers viewed the data to observe the students who obtained the referral.

9. Health center updated the data each month to identify the development of student reference number to health center.

10. Teachers conducted a follow-up through the agency against the students and their families regarding referral to the health center.

11. School parties were expected to proactively direct their students to conduct referrals in accordance with the schedule of treatment dates that had been agreed with the health center.

12. The school party should remind the students to bring school's health record book during a dental care reference at the health center.

The success indicators of the online communication forum empowerment program were as follows:

1. Dentists and dental nurses were able to access online communication forums through WhatsApp without constraints.

2. Student health unit/sport teachers were able to access online communication forum through social media WhatsApp without any constraints.

3. Student health unit/sport teachers were able to enter data in the form of student identity from all classes to online communication forum.

4. Dentists and dental nurses of health center could fill data result of periodic dental examination of elementary school children and child care, which will be referred to be given with treatment at health center to online communication forum.

5. Student health unit/sport teachers were able to understand all information from data submitted from the health center in online communication forum.

\section{RESULTS}

Evaluation for these targets was carried out through monitoring the mechanism of the ongoing online communication forum. The indicators set out in this program are a mechanism that is related to each other, which must be achieved entirely so that the dental communication forum can run well. The success indicator was dentist and dental nurse who were able to access online communication forum through WhatsApp without constraint, student health unit/sport teachers who were able to access online communication forum through WhatsApp without constraint, student health unit/sport teachers who were able to enter the data in the form of student identity from all classes to online communication forums, dentists and dental nurses of the health center who were able to include data on the results of regular dental checkups of elementary school children and child care that will be referred for treatment at health center to online communication forums, and student health unit/sport teachers who were able to understand all information from data submitted from the health center in online communication forums.

Before this empowerment program was held, doctors in public health center barely received any students' dental and oral health information from their school teacher. They only received the information from students who came to the public health center to receive dental treatment [Table 1].

\section{Discussion}

This activity was attended by targeted respondents, consisting of dentists and dental nurses of Balongsari Public Health Center, and teachers from six elementary schools. This activity began with counseling and training on the mechanism of online dental communication forum.

The aim of the counseling was giving school teachers the basic dental health knowledge. School teachers can provide dental health education and screening for any gross deposits of food and calculus. This proves to be a feasible and more effective way of imparting and educating children for good oral hygiene. In India, which is developing, programs can be organized to train teachers on a short-term basis. This can be incorporated as a part of the curriculum, which can bring about a change in oral hygiene behavior, which in turn can bring about a change in lifestyle practices. ${ }^{[8]}$

School teachers can play a major role in imparting dental health education to children by playing a vital role in planning and implementing oral health preventive programs. As children spend a considerable amount of time with teachers during their school education, it becomes the responsibility of the teachers by virtue of their training to impart such knowledge to the children..$^{[9,10]}$

Teachers of the Students Health Unit, in lieu of parents of children in school, also play an important role in instilling a preventive health culture for students. Schools are the

\begin{tabular}{lcc}
\hline $\begin{array}{l}\text { Table 1: Number of students' data collected in the public } \\
\text { health center before and after the WhatsApp Program }\end{array}$ \\
\hline \multicolumn{2}{c}{ Students' data collected } \\
\cline { 2 - 3 } & Before & After \\
\hline School A & 2 & 20 \\
School B & 0 & 20 \\
School C & 0 & 15 \\
School D & 1 & 26 \\
School E & 2 & 23 \\
School F & 0 & 21 \\
\hline
\end{tabular}


Kusumo, et al: : Social media as health discussion platform

one place where most school-age children congregate 6-7h a day, 9 months a year. Hence, in this study, an effort was made to assess school teacher's knowledge and factors affecting the knowledge concerning prevention about dental decay and malocclusion by means of self-administered questionnaire. ${ }^{[1]}$

With the online communication forum program, data on dental and oral health of elementary school students can be recorded well. With this program, the public health center can collect data on dental and oral health of elementary school children without having to bring children. Health teachers in the school can collect the data and then submit them to the public health center, so that data on dental and oral health of primary school children can be monitored by the public health center. A significant increase was observed in the amount of data obtained. From the indicators that have been set, the targets were able to gain success indicators that had been made. It means that the mechanism was executed as expected.

\section{Acknowledgement}

We would like to thank all the staff of the Department of Dental Public Health, Faculty of Dental Medicine, Universitas Airlangga, Surabaya, Indonesia.

\section{Financial support and sponsorship}

Nil.

\section{Conflicts of interest}

There are no conflicts of interest.

\section{References}

1. Trihono. National Basic Health Research 2013. Jakarta; Department of Indonesian Research and Health Development. 2013:110-111.

2. Umayal S, Gayathri R, Priya VV. Awareness on dental caries among adolescent population. Drug Invention Today 2018;10:1071-3.

3. Chambisha L, Anthony SN, Siziya S. Oral hygiene practices and oral health care seeking behaviours among primary school teachers in Ndola, Zambia. Tanzania Dent J 2017;20:16-21.

4. Acharya B, Maru D, Schwarz R, Citrin D, Tenpa J, Hirachan S, et al. Partnerships in mental healthcare service delivery in low-resource settings: Developing an innovative network in rural Nepal. Globalization Health 2017;13:2.

5. Simon AK, Rao A, Rajesh G, Shenoy R, Pai MB. Influence of oral health literacy on the oral health status of school teachers in Mangalore, India. J Indian Assoc Public Health Dent 2018;16:127.

6. Demirjian A, David B. Learning medical and dental sciences through interactive multi-media. Medinfo 1995;8:1705.

7. Balappanavar AY, Sardana V, Hegde P. Social networking and oral health education. Int J Sci Study 2013;1:16-9.

8. Byalakere RC, Suma S, Kaverikana K, Manjunath CB. The use of school teachers to promote oral hygiene in some secondary school students at Hyderabad, Andhra Pradesh, India: A short term prospective pilot study. J Family Community Med 2012;19:184-9.

9. Sekhar V, Sivsankar P, Easwaran MA, Subitha L, Bharath N, Rajeswary K, et al. Knowledge, attitude and practice of school teachers toward oral health in Pondicherry. J Clin Diag Res 2014;8:ZC12-5.

10. Preethi S. Dental health education and the role of teachers in imparting oral health education in Indian schools. J Educ Ethics Dent 2015;5:57-60.

11. Burt BA. How useful are cross-sectional data from surveys of dental caries? Community Dent Oral Epidemiol 1997;25:36-41. 